${ }^{1}$ Department of Paediatrics, Medical University of Silesia, Katowice, Poland

${ }^{2}$ Department of Diabetology and Internal Medicine, Pomeranian Medical University in Szczecin, Poland

${ }^{3}$ Medical University of Gdansk, Department and Clinic of Pediatrics, Diabetology and Endocrinology, Gdansk, Poland

${ }^{4}$ Poznan University of Medical Sciences, Department of Internal Medicine and Diabetology, Poland

${ }^{5}$ Department of Pediatrics, Oncology, Hematology and Diabetology, Medical University of Łódź, Poland

${ }^{6}$ Unit on Advanced Technologies in Diabetes, Department and Chair of Metabolic Diseases, Jagiellonian University, Krakow, Poland

\title{
The proposal of initial bolus calculator settings in Accu-Chek Combo system
}

\begin{abstract}
Bolus calculator feature (BC) is one of the most important options of modern insulin pumps. It enables both periprandial as well as correction insulin dosing. BC function leads to improvement of patient's metabolic control. It makes the treatment safer andlimits the number of hypoglycemic episodes. In presented article we propose preliminary setting of $B C$ in the Accu-Chek Combo system. It is obvious that those setting should be always verified according to a clinical situation. (Clin Diabet 2015; 4, 6: 251-253)
\end{abstract}

Key words: diabetes, insulin pump, bolus calculator

Bolus calculator feature $(B C)$ is one of the most important options of modern insulin pumps (IP) that optimizes the management of diabetes [1-5].

From patient's point of view as of the user of $B C$, its function is the exact calculation of the appropriate meal and/or correction bolus, based on the amount of active insulin calculated by the device. Using this option allows for a better metabolic control, and also affects the safety of the therapy, by reducing the risk of hypoglycemia $[2,3,6-13]$.

\section{Address for correspondence:}

prof. dr hab. n. med. Tomasz Klupa

Unit on Advanced Technologies in Diabetes

Department and Chair of Metabolic Diseases

Jagiellonian University, Krakow, Poland

Phone: +48 (12) 4248300

Fax: +48 (12) 4219786

e-mail: tomasz.klupa@uj.edu.pl

Clinical Diabetology 2015, 4, 6, 251-253

DOI: $10.5603 /$ DK.2015.0028

Received: 22.11 .2015

Accepted: 22.01.2016
For the doctor, $\mathrm{BC}$ is a valuable tool for accurate analysis of therapeutic actions taken by the patient $[2,3,8]$.

Personal insulin pump Accu-Chek Combo has a modern system of Bolus Advisor which allows the user to customize its settings $[3,5,6,8]$. Proper use of $B C$ can be based on the following principles:

- BC should be programmed and activated along with setting a patient on a pump for the first time;

- the patient must be clearly informed of the fact that the initial, empirical $B C$ settings may prove suboptimal for him;

- the first verification of the $B C$ settings should take place shortly after activation of this function (optimally within the first 1-2 weeks after connecting IP). Only after analysis of data from a personal insulin pump and possible modification of presets, the suggestions from $B C$ may be for the patient each time a reliable basis for making decisions about meal/corrective dose of insulin $[1,3,6]$.

The patient must be advised that in certain clinical situations he may not agree with a dose of insulin proposed by $B C$ and change it.

Analysis of the pump and record data from the meter should be based on data read from devices using a dedicated computer program.

It should be emphasized that the bolus calculator settings in individual personal insulin pumps are based on different, specific to a particular manufacturer algorithms. Therefore, each time there is a change of $I P$, the $B C$ settings must be re-evaluated, based on the algorithm used in patient's new device.

Below (Table 1) we present a proposal for the initial setup of the BC in Accu-Chek Combo system. These recommendations can serve as a starting point for the 
Table 1. The proposal of initial settings in BC of Accu-Chek Combo system

\begin{tabular}{|c|c|c|c|c|c|c|}
\hline \multirow[t]{2}{*}{ Parameter (available range) $^{1}$} & \multirow[t]{2}{*}{ Units } & \multicolumn{5}{|c|}{ Personal settings for given age } \\
\hline & & $1-6$ years & 7-11 years & $12-18$ years $^{2}$ & Adults & Pregnant \\
\hline \multicolumn{7}{|l|}{ Target range of bG } \\
\hline Lower limit (50-140) & $\mathrm{mg} / \mathrm{dl}$ & $80-100$ & $80-100$ & $80-100$ & $80-100$ & 60 \\
\hline Upper limit (100-300) & $\mathrm{mg} / \mathrm{dl}$ & $100-130$ & $100-130$ & $100-120$ & $100-120$ & 120 \\
\hline \multicolumn{7}{|l|}{ Carbohydrate unit } \\
\hline \multicolumn{6}{|l|}{$C C=15 \mathrm{~g})$} & KE (WW) \\
\hline $\mathrm{I}-\mathrm{CHO}(0,1-24)$ & $\mathrm{U} / \mathrm{KE}$ & Rule of 400 & Rule of 400 & Rule of 400 & Rule of 400 & Rule of 400 \\
\hline ISF (insulin: 0,1-50; bG: 1-999) & & Rule of 1800 & Rule of 1800 & Rule of 1800 & Rule of 1800 & Rule of 1800 \\
\hline \multicolumn{7}{|l|}{ Warning limits } \\
\hline Hyper (180-350) & $\mathrm{mg} / \mathrm{dl}$ & 250 & 250 & 250 & 250 & 180 \\
\hline Нyро (50-90) & $\mathrm{mg} / \mathrm{dl}$ & 60 & 60 & 50 & 50 & 50 \\
\hline \multicolumn{7}{|l|}{ Advice options } \\
\hline Meal rise (50-200) & $\mathrm{mg} / \mathrm{dl}$ & 80 & 80 & 50 & 50 & 50 \\
\hline Snack size $(0-2,4 \mathrm{WW})$ & KE & $0,5-1,0$ & $1,0-1,5$ & 2 & 2 & 2 \\
\hline Acting time $(1.5-8 \mathrm{~h})$ & $\mathrm{h}$ & $3 \mathrm{~h}$ & $3 \mathrm{~h}$ & $3 \mathrm{~h}$ & $3-5 h^{3}$ & $3-4 h^{3}$ \\
\hline $\begin{array}{l}\text { Offset time (from } 45 \text { min up } \\
\text { to „acting time") }\end{array}$ & $\mathrm{h}$ & $1,5 \mathrm{~h}$ & $1,5 \mathrm{~h}$ & $1 \mathrm{~h}$ & $1 \mathrm{~h}$ & $45 \min -1 h^{4}$ \\
\hline \multicolumn{7}{|l|}{ Health events } \\
\hline Exercise 1 & $\%$ & Indywidually & Indywidually & Indywidually & -20 & -20 \\
\hline Exercise 2 & $\%$ & Indywidually & Indywidually & Indywidually & -50 & -50 \\
\hline Stress & $\%$ & Indywidually & Indywidually & Indywidually & +20 & +20 \\
\hline Ilness 5 & $\%$ & Indywidually & Indywidually & Indywidually & $\begin{array}{c}\text { From }+20 \\
\text { to }+50\end{array}$ & $\begin{array}{c}\text { From }+20 \\
\text { to }+50\end{array}$ \\
\hline Premenstrual & $\%$ & - & Indywidually & Indywidually & +20 & - \\
\hline High bG reminder & Hours & After $1 \mathrm{~h}$ & After $1 \mathrm{~h}$ & After $1 \mathrm{~h}$ & After $1 \mathrm{~h}$ & After $1 \mathrm{~h}$ \\
\hline Low bG reminder & Minutes & After 15 min & After $15 \mathrm{~min}$ & After $15 \mathrm{~min}$ & After $15 \mathrm{~min}$ & After $15 \mathrm{~min}$ \\
\hline
\end{tabular}

${ }^{1}$ Explanations of particular functions of BC is included in the user manual

${ }^{2}$ Settings may be used as in the case of adults

${ }^{3}$ Depending on bolus dose $3 \mathrm{~h}<10 \mathrm{U}, 4 \mathrm{~h}<10-20 \mathrm{U}, 5 \mathrm{~h}>20 \mathrm{U}$

${ }^{4}$ Depending on trimester

${ }^{5}$ Excluding diseases of digestive system

implementation of the BC functions. However, please do not treat these proposals doctrinally, as they may be modified in appropriate clinical situations.

\section{Conflict of interest}

The article was sponsored by Roche Diabetes Care Polska Sp. z o.o.

\section{REFERENCES}

1. Shashaj E, Busetto E, Sulli N. Treatment Benefits of a bolus calculator in pre- and postprandial glycaemic control and meal flexibility of paediatric patients using continuous subcutaneous insulin infusion (CSII) B. Diabetic Medicine 2008; 25: 1036-1042.

2. Colin IM, Paris I. Glucose meters with built-in automated bolus calculator: gadget or real value for insulin-treated diabetic patients? Diabetes Ther 2013; 4: 1-11.

3. Klonoff DC. The current status of bolus calculator decision-support software. Diabetes Sci Technol 2012; 6: 990-994.
4. Sussman A, Taylor EJ, Patel M et al. Performance of a glucose meter with a built-in automated bolus calculator versus manual bolus calculation in insulin-using subjects. J Diabetes Sci Technol 2012; 6: 339-344.

5. Schmidt S, Meldgaard M, Serifovski N et al. Use of an automated bolus calculator in MDI-treated type 1 diabetes: the BolusCal Study, a randomized controlled pilot study. Diabetes Care 2012; 35: 984-990.

6. Zisser H, Wagner R, Pleus $\mathrm{S}$ et al. Clinical Performance of Three Bolus Calculators in Subjects with Type 1 Diabetes Mellitus: A Head-to-Head-to-Head Comparison. Diabetes Technol Ther 2010; 12: 955-961.

7. Barnard K, Parkin C, Young A, Ashraf M. Use of an automated bolus calculator reduces fear of hypoglycemia and improves confidence in dosage accuracy in T1DM patients treated with multiple daily insulin injections. J Diabetes Sci Technol 2011; 6: 144-149.

8. Schwartz FL, Guo A, Marling CR, Shubrook JH. Analysis of use of an automated bolus calculator reduces fear of hypoglycemia and improves confidence in dosage accuracy in type 1 diabetes mellitus patients treated with multiple daily insulin injections. J Diabetes Sci Technol 2012; 6: 150-152. 
9. Matejko B, Grzanka M, Kieć-Wilk B, Małecki MT, Klupa T. Clinical factors affecting the perception of hypoglycemia in type 1 diabetes patients treated with personal insulin pumps. Ann Agric Environ Med 2013; 20: 152-154.

10. Rossetti P, Vehí J, Revert A, Calm R, Bondia J. Commentary on "Performance of a glucose meter with a built-in automated bolus calculator versus manual bolus calculation in insulin-using subjects". J Diabetes Sci Technol 2012; 6: 345-347.
11. Walsh J, Roberts $R$, Bailey $T$ Guidelines for optimal bolus calculator settings in adults. J Diabetes Sci Technol 2011; 5: 129-135.

12. Shapira G, Yodfat O, HaCohen A, Feigin P, Rubin R. Bolus guide: a novel insulin bolus dosing decision support tool based on selection of carbohydrate ranges. J Diabetes Sci Technol 2010; 4: 893-902.

13. Pańkowska E, Błazik M. Bolus calculator with nutrition database software, a new concept of prandial insulin programming for pump users. J Diabetes Sci Technol 2010; 4: 571-576. 
